\title{
Prevalence and correlates of transactional sex among women of low socioeconomic status in Portland, OR
}

Timothy W. Menza ${ }^{1,2,3^{*}}$ (D) Lauren Lipira ${ }^{4}$, Amisha Bhattarai ${ }^{4}$, Victoria Cali-De Leon ${ }^{4}$ and E. Roberto Orellana ${ }^{4}$

\begin{abstract}
Background: Women who report transactional sex are at increased risk for HIV and other sexually transmitted infections (STIs). However, in the United States, social, behavioral, and trauma-related vulnerabilities associated with transactional sex are understudied and data on access to biomedical HIV prevention among women who report transactional sex are limited.
\end{abstract}

Methods: In 2016, we conducted a population-based, cross-sectional survey of women of low socioeconomic status recruited via respondent-driven sampling in Portland, Oregon. We calculated the prevalence and, assessed the correlates of, transactional sex using generalized linear models accounting for sampling design. We also compared health outcomes, HIV screening, and knowledge and uptake of HIV pre-exposure prophylaxis (PrEP) between women who did and did not report transactional sex.

Results: Of 334 women, 13.6\% reported transactional sex (95\% confidence interval [Cl]: 6.8, 20.5\%). Women who reported transactional sex were older, more likely to identify as black, to identify as lesbian or bisexual, to experience childhood trauma and recent sexual violence, and to have been homeless. Six percent (95\% Cl: 1.8, 10.5\%) of women with no adverse childhood experiences (ACEs) reported transactional sex compared to $23.8 \%$ (95\% Cl: 13.0, 34.6\%) of women who reported eleven ACEs $(P<0.001)$. Transactional sex was strongly associated with combination methamphetamine and opiate use as well as condomless sex. Women who reported transactional sex were more likely to report being diagnosed with a bacterial STI and hepatitis C; however, HIV screening and pre-exposure prophylaxis knowledge and use were low.

Conclusions: In a sample of women of low socioeconomic status in Portland, Oregon, transactional sex was characterized by marginalized identities, homelessness, childhood trauma, sexual violence, substance use, and sexual vulnerability to HIV/STI. Multi-level interventions that address these social, behavioral, and trauma-related factors and increase access to biomedical HIV prevention are critical to the sexual health of women who engage in transactional sex.

Keywords: Transactional sex, Adverse childhood experiences, HIV testing, Pre-exposure prophylaxis, Substance use

\footnotetext{
* Correspondence: timothy.w.menza@dhsoha.state.or.us

'HIV/STD/TB Section, Public Health Division, Oregon Health Authority, 800 NE

Oregon Street, Portland, Oregon 97232, USA

${ }^{2}$ Oregon Health \& Sciences University (OHSU), Portland, Oregon, USA

Full list of author information is available at the end of the article
} 


\section{Background}

The incidence of HIV in the United States (U.S.) has remained stable in the past few years and HIV diagnoses among women have been in decline [1]. However, certain subpopulations of women (e.g., women of color, women with low income or low education, and women who inject drugs) are still at considerable risk for HIV [2]. Research on social and structural forces that increase vulnerability for $\mathrm{HIV}$ and other sexually transmitted infections (STIs) among women has demonstrated that a multitude of factors, including minority status, low socioeconomic status (SES), and adverse experiences, intersect to create milieus of risk where women, especially women of color, are at a disadvantage when it comes to avoiding HIV and STI [2, 3].

Women who engage in transactional sex may be at particularly high risk for HIV infection. Transactional sex, or sex exchanged for money, goods, services, and/or status, is a complex phenomenon [4]. A 2016 metaanalysis of 14 studies of women who reported exchanging sex for money or drugs in the U.S. found a pooled HIV prevalence of $17.3 \%$ [5], compared to a prevalence of $0.16 \%$ in U.S. women [1].

Estimates of the prevalence of transactional sex among women in the U.S. range from 4 to $41 \%$ [6-12]. However, no studies have estimated the prevalence of transactional sex in the Pacific Northwest, a region with rising homelessness and injection drug use, factors strongly associated with transactional sex and recent increases in HIV infection [13-15].

Indeed, prior studies indicate that women with certain characteristics are more likely to engage in transactional sex that others. Compared to women who did not report transactional sex, those who did were more likely to use substances and to report recent criminal justice involvement [11]; to experience homelessness [7, 10]; and, to face sexual intimate and commercial partner violence $[8,9$, 16]. Moreover, women who engage in transactional sex may also be more likely to have had early adverse experiences. Growing research indicates that trauma throughout the lifespan is associated with HIV-related risk factors, including drug use, mental health problems, homelessness, and condomless sex [17] and women living with HIV report higher rates of trauma and violence than the general population of U.S. women [18]. This overlap of transactional sex, trauma, and HIV-related vulnerability is likely most acute among women of low SES [8, 19, 20].

While many studies have demonstrated an association between transactional sex and HIV prevalence among women in the U.S., most of those studies were conducted over 20 years ago [5]. Since that time, there have been key advances in HIV prevention and treatment, including HIV treatment as prevention, undetectable equals un-transmittable, and HIV pre-exposure prophylaxis. Analysis of more current data is needed to better understand HIV risk and prevention behaviors and related health outcomes among women who engage in transactional sex in the modern era.

In the current study, we determined the prevalence and correlates of transactional sex among women of low SES in the Portland, Oregon metropolitan area. We also examined the relationship of transactional sex and HIV/ STI-related prevention and health outcomes.

\section{Methods}

We conducted a cross-sectional analysis of a sample of women of low SES as part of the 2016 Centers for Disease Control and Prevention (CDC) National HIV Behavioral Surveillance (NHBS) heterosexual cycle in the Portland, Oregon, metropolitan area [21, 22]. We focused our work on women of low SES due to well-documented intersections between poverty, transactional sex, and HIV-related risk behaviors [2, 3, 8, 19, 20, 23].

We recruited participants via respondent-driven sampling (RDS) [24]. Recruitment began with fifteen initial participants, or seeds. Eligible seeds who completed the survey were provided three to five coded coupons to recruit others (i.e., recruits). Eligible recruits completed the survey and, in turn, recruited three to five additional participants.

Per CDC protocol, participants were eligible if they were aged 18-60 years; identified as cis-gender female; resided in a census tract of the Portland-Hillsboro, Oregon-Vancouver, Washington, U.S. metropolitan statistical area (MSA); did not previously participate in the current survey cycle; were able to complete the survey in English or Spanish; reported sex with at least one opposite sex partner in the prior 12 months; and, reported an income below the federal poverty level or completed less than a high school education (i.e., low SES). Also, per CDC protocol, individuals who identified as transgender or had sex with a same sex partner, but not an opposite sex partner, in the prior 12 months were not eligible for participation.

Eligible participants completed an anonymous face-toface computer-assisted survey that captured information about social, economic, and behavioral vulnerability to HIV infection and access to HIV testing, care, and prevention. Participants were remunerated for their participation ( $\$ 50$ for completing the interview and $\$ 25$ for rapid HIV testing).

\section{Measures \\ Transactional sex}

We created a binary variable that categorized participants who reported receiving money or drugs for sex from one or more casual sex partners in the prior 12 months as having engaged in transactional sex. Participants were not asked if they received money or drugs for sex from main sex partners. 


\section{HIV testing, HIV prevention, and health outcomes}

We assessed HIV testing, knowledge of HIV PrEP, and use of PrEP in the prior 12 months. We also asked participants whether they had been ever diagnosed with hepatitis $\mathrm{C}$ and whether they had been diagnosed with gonorrhea, chlamydia, or syphilis in the prior 12 months.

\section{Socio-demographics}

The survey instrument captured age, race/ethnicity, sexual orientation, education, employment, income, homelessness, and incarceration history.

\section{Trauma}

We used the 11-item Adverse Childhood Experiences (ACEs) questionnaire to assess experiences of emotional, physical, and sexual abuse (2 items); physical and emotional neglect; parental separation or divorce; and, household substance use, mental illness, partner violence, and incarceration prior to age 18 [25]. To assess the cumulative effects of ACE, we tallied the number of ACE endorsed by each participant to create a continuous variable ranging from zero to eleven. We also inquired about sexual intimate partner violence in the prior 12 months.

\section{Substance use}

We inquired about injection drug use and non-injection use of methamphetamine and opiates (i.e., heroin, prescription opioid pain medications) in the past 12 months.

\section{Sexual behavior}

We asked women to enumerate their sexual partners and queried whether they had had condomless vaginal or anal sex with a casual partner in the prior 12 months.

\section{Statistical analyses \\ Prevalence of transactional sex}

As each participant had a different sampling probability based on their network size, we calculated Gile successive sampling (SS) weights for each participant using RDS Analyst [26, 27]. We based our weights on the American Community Survey (ACS) 2011-2015 population estimates of people aged 18-64 living below the federal poverty level in the Portland-Hillsboro, Oregon-Vancouver, Washington, U.S. MSA (161,186 individuals) [28]. We estimated that $82 \%$ were sexually active in the prior 12 months [29]. Thus, our base population for weight calculations was $0.82^{*} 161,186=132,173$. We calculated weighted medians and interquartile ranges (IQRs) and proportions and bootstrap 95\% confidence intervals (CIs) for continuous and categorical variables, respectively.

\section{Correlates of transactional sex}

To determine correlates of transactional sex, we first compared characteristics of women who engaged in transactional sex to characteristics of women who did not engage in transactional sex. We used design-based chi-squared tests and tests of medians to compare categorical and continuous variables, respectively. Then, we ran multivariable analyses. To accommodate a potentially small number of women reporting transactional sex and avoid an overfit multivariable model [30], we limited our number of potential covariates to the ten that we thought would be most highly associated with transactional sex: age, race/ethnicity, sexual orientation, homelessness, incarceration, ACEs score, sexual violence, injection drug use, methamphetamine and opiate use, and condomless vaginal or anal sex with a casual partner in the prior 12 months.

We created four multivariable models. Model 1 included age, race/ethnicity, sexual orientation, homelessness, and incarceration. Model 2 added ACEs score and sexual violence to Model 1 . Model 3 added substance use associated with transactional sex to Model 2. Model 4 added sexual behavior associated with transactional sex to Model 3. We used generalized linear models with a $\log$ link and a Poisson distribution to estimate risk ratios (RRs) and bootstrap 95\% CIs. Multivariable models were adjusted for network size, used sampling weights, and calculated standard errors based on clustered sampling by recruitment chain.

We computed the variance inflation factor (VIF) and tolerance (1/VIF) for each of the ten predictors included in Model 4 to assess for collinearity [31]. All tolerance values were less than 0.1 , indicating that each predictor was unlikely to be a linear combination of the others.

\section{Engagement in HIV testing and prevention, and health outcomes}

We compared the binary outcomes of HIV testing, hearing about and taking PrEP, and diagnoses of hepatitis $\mathrm{C}$ and bacterial STI between women who reported transactional sex and those who did not using design-based chi-squared tests.

We used RDS Analyst [26] and STATA 15.1 (College Station, TX) for all analyses with statistical significance defined as $P<0.05$.

\section{Results}

As part of the 2016 NHBS heterosexual cycle in Portland, we screened 385 women of whom 334 (87\%) were eligible and completed the survey. Of the 51 who were not eligible to participate, 31 (61\%) did not report a male sex partner, $9(18 \%)$ were previous participants, $7(14 \%)$ were over age 60 , and $3(6 \%)$ were not alert enough to complete the survey (categories not mutually exclusive).

The median age of eligible women was 35 years (IQR: 23, 46; Table 1). Sixty-eight percent were women of color, $42.9 \%$ percent were black. Most identified as 
Table 1 Selected characteristics of women who did and did not report transactional sex in the prior 12 months among women participating in National HIV Behavioral Surveillance, Portland, Oregon, United States, $2016^{\text {a }}$

\begin{tabular}{|c|c|c|c|c|}
\hline & Total, \% & No transactional sex, \% & Transactional sex, \% & $P$ value \\
\hline \multicolumn{5}{|l|}{ Socio-demographics } \\
\hline Age, median (IQR) & $35(23,46)$ & $34(23-45)$ & $40(30-46)$ & 0.066 \\
\hline Race/ethnicity & & & & 0.395 \\
\hline White & $32.0(22.6,41.0)$ & $29.5(20.2,38.9)$ & $45.9(20.7,71.2)$ & \\
\hline Black & $42.9(34.5,51.2)$ & $44.3(35.0,53.6)$ & $34.2(13.1,55.2)$ & \\
\hline Latina/x & $8.3(4.2,12.5)$ & $7.9(4.0,11.8)$ & $11.2(1.9,28.7)$ & \\
\hline Other, multiracial & $17.0(10.8,23.2)$ & $18.3(12.1,24.5)$ & $8.7(3.1,17.7)$ & \\
\hline Sexual orientation & & & & $<0.001$ \\
\hline Heterosexual & $82.2(75.6,88.7)$ & $88.4(84.0,92.7)$ & $42.9(20.0,65.8)$ & \\
\hline Lesbian, bisexual & $17.8(10.2,26.8)$ & $11.6(7.3,16.0)$ & $57.1(34.2,80.0)$ & \\
\hline Homeless, past 12 months & & & & $<0.001$ \\
\hline No & $63.3(55.3,71.3)$ & $69.8(61.6,77.9)$ & $22.6(5.6,39.7)$ & \\
\hline Yes & $36.7(28.2,45.1)$ & $30.2(22.1,38.4)$ & $77.4(60.3,94.4)$ & \\
\hline Ever incarcerated & & & & $<0.001$ \\
\hline No & $57.4(48.0,65.1)$ & $64.1(55.5,71.9)$ & $17.8(7.8,35.7)$ & \\
\hline Yes & $42.6(34.1,51.1)$ & $35.9(28.1,44.4)$ & $82.2(64.3,92.2)$ & \\
\hline \multicolumn{5}{|l|}{ Trauma } \\
\hline ACE score, median (IQR) & $4(2-7)$ & $4(2-7)$ & $7(6-9)$ & $<0.001$ \\
\hline Sexual intimate partner violence, past 12 months & & & & $<0.001$ \\
\hline No & $85.8(79.2,91.6)$ & $92.3(86.5,95.7)$ & $45.9(24.2,69.1)$ & \\
\hline Yes & $14.2(8.9,21.7)$ & $7.7(4.3,13.5)$ & $54.2(30.9,75.8)$ & \\
\hline \multicolumn{5}{|l|}{ Substance use and sexual behaviors } \\
\hline Ever used drugs by injection & & & & $<0.001$ \\
\hline No & $84.5(78.8,90.7)$ & $91.9(85.5,94.5)$ & $43.1(22.8,66.1)$ & \\
\hline Yes & $14.5(8.2,20.8)$ & $8.1(4.4,14.5)$ & $56.9(33.8,77.2)$ & \\
\hline Methamphetamine and opiate use, past 12 months & & & & $<0.001$ \\
\hline None & $74.2(67.1,81.3)$ & $82.1(75.6,87.2)$ & $25.8(10.8,44.1)$ & \\
\hline Methamphetamine only & $10.8(4.5,17.2)$ & $8.0(4.9,12.9)$ & $29.9(7.6,58.9)$ & \\
\hline Opiates only & $6.8(3.8,9.9)$ & $5.8(2.9,11.5)$ & $14.5(3.6,25.3)$ & \\
\hline Methamphetamine and opiates & $7.3(3.0,11.7)$ & $3.9(2.0,7.5)$ & $29.8(6.3,53.3)$ & \\
\hline $\begin{array}{l}\text { Condomless vaginal or anal sex with a casual partner, } \\
\text { past } 12 \text { months }\end{array}$ & & & & $<0.001$ \\
\hline No & $59.4(51.9,67.0)$ & $68.0(59.7,76.2)$ & $5.4(1.3,12.1)$ & \\
\hline Yes & $40.6(32.8,48.3)$ & $32.0(23.7,40.3)$ & $94.6(87.9,99.9)$ & \\
\hline
\end{tabular}

ACE Adverse childhood experience, $C I$ Confidence interval, IQR Interquartile range

${ }^{a}$ All data are percentages $(95 \% \mathrm{Cl})$ unless otherwise noted; medians and percentages are weighted

heterosexual, while $1.4 \%$ identified as lesbian and $16.4 \%$ as bisexual. Almost $40 \%$ had been homeless in the prior 12 months. Only one-third were employed and almost one-fourth did not complete high school. Forty-three percent reported ever being incarcerated. Eighty-one percent were living in poverty.

Ninety-two percent of women reported $\geq 1$ ACEs, $70.7 \%$ reported $\geq 3 \mathrm{ACEs}$, and $10.5 \%$ reported $\geq 9$ ACEs; median ACE score was 4 [2-7]. Fourteen percent experienced sexual intimate partner violence in the prior 12 months. Fourteen percent had ever used drugs by injection and $26 \%$ used non-injection methamphetamine, opiates, or both. Women reported a median of 2 sexual partners (IQR: $1-3$ ) and $40.6 \%$ reported condomless vaginal or anal sex with a casual partner.

Of the 334 women, 241 (65.1\%) reported testing HIVnegative prior to survey participation, $2(0.3 \%)$ reported 
testing HIV-positive, and 94 (34.6\%) had never been tested or did not know their results. Based on point-ofcare HIV testing, 329 (99.6\%) results were negative, one $(0.3 \%)$ was positive, and four $(0.1 \%)$ were indeterminate or missing.

\section{Prevalence and correlates of transactional sex}

Approximately $14 \%$ of women reported transactional sex in the prior 12 months (13.6, 95\% CI: 6.8, 20.5\%). Women who reported transactional sex were less likely to identify as heterosexual, and more likely to report homelessness and incarceration (Table 1). Those who reported transactional sex reported also more ACEs and were more likely to experience recent sexual violence. Women who reported transactional sex were more likely to use drugs by injection and use non-injection methamphetamine, opiates, or both. Women who reported transactional sex were more likely to report condomless sex with a casual partner.

In Model 1, women who were older, black, bisexual or lesbian, experienced homelessness in the prior 12 months, and were ever incarcerated were more likely to report transactional sex (Table 2). In Models 2 and 3, women who were older, black, lesbian or bisexual, experienced homelessness in the prior 12 months, and who had a greater number of ACEs and who experienced sexual violence were more likely to report transactional sex.

In Model 4, a one-year increase in age was associated with a $3 \%(95 \%$ CI: $1-7 \%)$ increase in the probability of reporting transactional sex comparing older women to younger women. Black women were more likely to report transactional sex compared to their white counterparts. For a one-point increase in the ACEs score, the probability of reporting transactional sex was $12 \%$ (95\%: 3-21\%) higher comparing women with a higher score to women with a lower score. Women who reported recent sexual violence were two times more likely to report transactional sex compared to women who did not report sexual violence. Women who used both methamphetamine and opiates were more likely to report transactional sex compared to women who used neither. Reporting condomless sex with a casual partner was associated with a 9-fold higher probability of transactional sex.

\section{Adverse childhood experiences and transactional sex}

In a post hoc analysis, we examined the crude and predicted proportions of women reporting transactional sex

Table 2 Multivariable models of correlates of transactional sex among women participating in National HIV Behavioral Surveillance, Portland, Oregon, United States, 2016

\begin{tabular}{|c|c|c|c|c|c|c|c|c|c|c|c|c|}
\hline & \multicolumn{3}{|c|}{ Model 1} & \multicolumn{3}{|c|}{ Model 2} & \multicolumn{3}{|c|}{ Model 3} & \multicolumn{3}{|c|}{ Model 4} \\
\hline & aRR & $95 \% \mathrm{Cl}$ & $P$ value & aRR & $95 \% \mathrm{Cl}$ & $P$ value & aRR & $95 \% \mathrm{Cl}$ & $P$ value & aRR & $95 \% \mathrm{Cl}$ & $P$ value \\
\hline Age & 1.03 & $1.01,1.07$ & 0.014 & 1.04 & $1.01,1.06$ & 0.003 & 1.04 & $1.01,1.07$ & 0.019 & 1.03 & $1.01,1.06$ & 0.039 \\
\hline \multicolumn{13}{|l|}{ Race/ethnicity } \\
\hline White & REF & & & REF & & & REF & & & REF & & \\
\hline Black & 1.87 & $1.01,3.48$ & 0.048 & 3.16 & $1.70,5.87$ & $<0.001$ & 3.96 & $2.11,7.46$ & $<0.001$ & 3.60 & $2.17,6.00$ & $<0.001$ \\
\hline Latina/x & 1.58 & $0.59,4.20$ & 0.360 & 1.17 & $0.52,2.64$ & 0.703 & 1.33 & $0.62,2.84$ & 0.460 & 1.13 & $0.54,2.38$ & 0.742 \\
\hline Other, multiracial & 0.72 & $0.27,1.94$ & 0.515 & 0.97 & $0.34,2.76$ & 0.949 & 1.03 & $0.40,2.63$ & 0.954 & 0.98 & $0.39,2.46$ & 0.969 \\
\hline Lesbian, bisexual ( $v$ heterosexual) & 4.21 & $2.36,7.82$ & $<0.001$ & 2.71 & $1.44,5.10$ & 0.002 & 2.14 & $1.19,3.85$ & 0.011 & 1.68 & $1.06,2.69$ & 0.028 \\
\hline Homeless, past 12 months & 3.53 & $1.86,6.68$ & $<0.001$ & 2.74 & $1.62,4.63$ & $<0.001$ & 2.53 & $1.50,4.25$ & $<0.001$ & 2.65 & $1.62,4.34$ & $<0.001$ \\
\hline Ever incarcerated & 2.80 & $1.08,7.31$ & 0.035 & 1.98 & $0.78,5.01$ & 0.152 & 1.63 & $0.62,4.27$ & 0.319 & 1.70 & $0.71,4.08$ & 0.233 \\
\hline ACE score & & & & 1.25 & $1.10,1.41$ & $<0.001$ & 1.20 & $1.07,1.34$ & 0.001 & 1.12 & $1.04,1.22$ & 0.005 \\
\hline $\begin{array}{l}\text { Sexual intimate partner violence, } \\
\text { past } 12 \text { months }\end{array}$ & & & & 3.33 & $1.76,6.31$ & $<0.001$ & 2.84 & $1.62,5.00$ & $<0.001$ & 2.07 & $1.24,3.46$ & 0.006 \\
\hline Ever used drugs by injection & & & & & & & 1.69 & $0.86,3.30$ & 0.126 & 1.44 & $0.77,2,68$ & 0.250 \\
\hline \multicolumn{13}{|l|}{$\begin{array}{l}\text { Methamphetamine and opiate use, } \\
\text { past } 12 \text { months }\end{array}$} \\
\hline None & & & & & & & REF & & & REF & & \\
\hline Methamphetamine only & & & & & & & 1.52 & $0.66,3.44$ & 0.328 & 1.26 & $0.61,2.62$ & 0.534 \\
\hline Opiates only & & & & & & & 1.76 & $0.70,4.42$ & 0.229 & 1.54 & $0.67,3.55$ & 0.310 \\
\hline Methamphetamine and opiates & & & & & & & 2.82 & $1.38,5.76$ & 0.004 & 2.45 & $1.44,4.14$ & 0.001 \\
\hline $\begin{array}{l}\text { Condomless anal or vaginal sex with } \\
\text { a casual partner, past } 12 \text { months }\end{array}$ & & & & & & & & & & 8.71 & $2.31,32.7$ & 0.001 \\
\hline
\end{tabular}


associated with each ACE score (Fig. 1). The predicted proportion of women reporting transactional sex was 6.1\% (95\% CI: 1.8, 10.5\%) for an ACEs score of zero compared to $23.8 \%$ (95\% CI: $13.0,34.6 \%$ ) for an ACEs score of 11 .

Women who reported transactional sex were more likely to report each of the 11 ACEs queried. However, compared to women who did not report transactional sex women who reported transactional sex were statistically significantly more likely to report that they lived with someone who was depressed, mentally ill or suicidal $(37.6 \% \mathrm{v}$. $69.9 \%, P=0.005)$; that a parent or adult in their home swore at them, insulted them, or put them down $(58.4 \% \mathrm{v}$. $83.3 \%, P=0.017$ ); and, that someone at least 5 years older than the respondent or an adult touched them sexually (42.9\% v. $82.2 \%, P<0.001$ ), tried to make the respondent
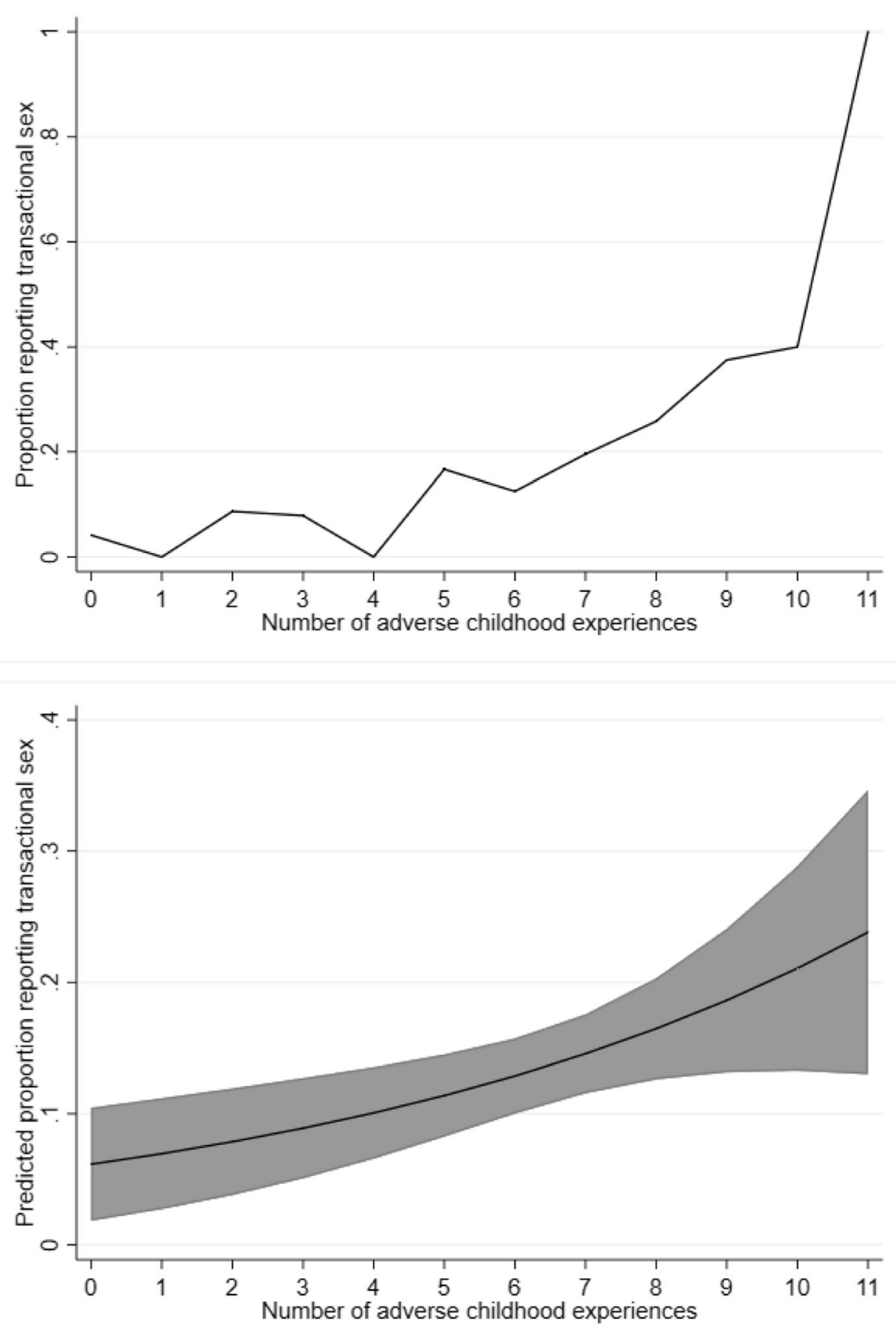

Fig. 1 Actual (a) and predicted (b) proportion of women reporting transactional sex according to number of adverse childhood experiences, National HIV Behavioral Surveillance, Portland, Oregon, United States, 2016 
touch them sexually $(29.2 \%$ v. $71.1 \%, P<0.001)$, or forced the respondent to have sex $(26.3 \%$ v. $77.9 \%, P<0.001)$.

\section{HIV prevention behaviors and health outcomes}

Less than a third of women in the total sample reported an HIV test in the prior 12 months (Table 3) and there was no difference in testing comparing women who did and did not report transactional sex. Only 3.9\% had heard of PrEP and $0.8 \%$ had taken PrEP in the prior 12 months. There was no difference in PrEP knowledge between women who did and did not report transactional sex, but statistically significantly fewer women who reported transactional sex reported taking PrEP in the prior 12 months compared to women who did not report transactional sex $(0 \%$ v. $1.0 \%, P<0.001)$. In contrast, $29.1 \%$ of those who reported transactional sex reported a hepatitis $\mathrm{C}$ diagnosis compared to $6.1 \%$ of those who did not report transactional sex $(P=0.001)$. Women who reported transactional sex were twice as likely to report a diagnosis of a bacterial STI in the past 12 months compared to women who reported no transactional sex, but this difference was not statistically significant $(P=0.132)$. Only one woman in the sample tested HIV-positive by rapid testing and she did not report transactional sex.

Healthcare access does not seem to explain testing and PrEP access outcomes. Of the entire sample, 90.4, 91.0, and $88.6 \%$ of the sample had health insurance, had a regular source of care, and saw a healthcare provider in the prior year, respectively. There were no statistically significant differences in these variables between women who did and did not report transactional sex.

\section{Discussion}

In a sample of low-SES women from the Portland, Oregon metropolitan area, $13.6 \%$ reported receiving money or drugs for sex in the prior 12 months. This estimate of transactional sex is similar to studies with similar inclusion/exclusion criteria conducted on the West Coast of the U.S. [7-9] but lower than estimates in U.S. East Coast samples [10-12] and a national U.S. sample [6]. Similar to prior studies, Black women, older women, and women who reported sexual violence were more likely to report transactional sex $[7,9,10,12,16]$.

Childhood trauma was pervasive among the women in our sample. Over $90 \%$ of women experienced $\geq 1 \mathrm{ACE}$, an estimate significantly higher than recent prevalence estimates among U.S. adults [32]. Furthermore, ACEs were associated with an increased probability of transactional sex independent of the effects of demographics, incarceration, homelessness, substance use, sexual behavior, and recent sexual intimate partner violence. Experiences of childhood sexual abuse were not the only ACEs associated with transactional sex; women who reported transactional sex were more likely to experience emotional abuse and to report living with a family member with mental illness. We observed a dose-response relationship between ACEs and the likelihood of transactional sex.

Our findings are consistent with the 2012 Behavioral Risk Factor Surveillance Survey (BRFSS), wherein women who experienced more ACEs were more likely to report a composite outcome of HIV risk behavior that included exchange sex [17] and a study of South African women which found an association between a different childhood trauma score and transactional sex [33, 34]. Similar dose-response relationships have been found with myriad other behaviors and physical and mental health outcomes [35]. The development of life coursebased, public health interventions to address the effects of trauma and harness the resilience that can come from surviving trauma are essential [36].

Women who reported both opioid and methamphetamine use were more likely to report transactional sex than women who used neither or either substance. In Oregon and other U.S. jurisdictions, there has been increasing overlap of methamphetamine and opioid use since at least 2011 [37-39]. Use of opioids and methamphetamine may produce a desirable, synergistic high; women who have experienced trauma may only be able to have sex while on methamphetamine; methamphetamine may mitigate opioid withdrawal symptoms; methamphetamine may be less stigmatized and easier to obtain; methamphetamine may allow people to function to complete daily task; and/or, methamphetamine may be

Table 3 HIV testing, knowledge and use or pre-exposure prophylaxis, and diagnosis of hepatitis C and bacterial sexually transmitted infection among women participating in National Behavioral Surveillance, Portland, Oregon, United States, $2016^{\text {a }}$

\begin{tabular}{llllll}
\hline Transactional Sex & $\begin{array}{l}\text { HIV test, past } \\
\mathbf{1 2} \text { months, } \% \\
\mathbf{9 5 \%} \mathbf{~ C l})\end{array}$ & $\begin{array}{l}\text { Heard of PrEP, ever, } \\
\mathbf{\%}(\mathbf{9 5} \% \mathbf{C l})\end{array}$ & $\begin{array}{l}\text { Took PrEP, past 12 } \\
\text { months, \% (95\% Cl) }\end{array}$ & $\begin{array}{l}\text { Diagnosed HCV, } \\
\text { ever, \% (95\% Cl) }\end{array}$ & $\begin{array}{l}\text { Bacterial STI, past 12 } \\
\text { months, \% (95\% Cl) }\end{array}$ \\
\hline No & $25.5(19.1,31.9)$ & $3.5(1.2,5.8)$ & $1.0(0.2,4.0)$ & $5.9(2.3,9.5)$ & $4.5(1.7,7.4)$ \\
Yes & $22.6(5.1,40.1)$ & $5.6(1.5,12.7)$ & 0.0 & $28.8(7.1,50.6)$ & $10.7(0.1,21.2)$ \\
Total & $25.1(18.8,31.4)$ & $3.8(1.6,6.0)$ & $0.8(0.2,1.9)$ & $9.0(4.5,13.6)$ & $5.4(2.7,8.0)$ \\
$P$ value & 0.761 & 0.532 & $<0.001$ & 0.001 & 0.132 \\
\hline
\end{tabular}

${ }^{a}$ All data are weighted percentages. CI Confidence interval, HCV Hepatitis C virus, PrEP Pre-exposure prophylaxis, STI Sexually transmitted infection 
used as a form of currency [40]. The implications of this overlap for sexual health require further investigation.

Despite clear indications for frequent HIV testing and PrEP, access to, and uptake of, biomedical prevention among women who reported transactional sex was limited. Self-reported condomless sex with a casual partner, hepatitis $C$ infection, and bacterial STI were nine, five, and two times more likely among women who reported transactional sex, respectively. However, among women who reported transactional sex, only $23 \%$ tested for HIV in the past year, 6\% had ever heard of PrEP, and none had taken PrEP. Research indicates that women vulnerable to HIV infection view PrEP as an important HIV prevention option, but may not be hearing about PrEP from their providers [41]. These data behoove medical and public health communities to develop programs to increase knowledge of, and access to, screening and biomedical HIV prevention as part of comprehensive sexual health services for HIVvulnerable women.

Our study has several limitations. First, NHBS is cross-sectional; we cannot infer a causal relationship between the examined vulnerabilities, behaviors, and health outcomes and transactional sex. Second, the assessment of ACEs and other variables was retrospective and subject to recall bias [42]. Third, the definition of transactional sex is too narrow and does not capture the range of practices that comprise transactional sex. Thus, the study may underestimate the prevalence of transactional sex and the context of the transactional sex practices captured in this study may not generalize to the context of other transactional sex practices. Fourth, the sample of women reporting transactional sex was relatively small, limiting our statistical models to a select set of variables to avoid overfitting. Fifth, while RDS strives to yield a probability sample of the target population, existing estimators rely heavily on the assumptions of the underlying network structure and of how that network is sampled [43]. Therefore, we cannot be certain that the sample we recruited truly represents the underlying population of women of low SES in Portland, Oregon. Furthermore, we recruited a racially diverse population rarely represented in Portland, Oregon, but, again, our sample may not be representative of the area.

\section{Conclusion}

In a sample of women of low SES in Portland, Oregon, transactional sex was characterized by marginalized identities, homelessness, childhood trauma, sexual violence, substance use, and sexual vulnerability to HIV/ STI. Public health efforts to reduce HIV-related health disparities and health inequities among women in the U.S. are unlikely to be effective if the social and structural factors that increase vulnerability to HIV/STIs are not addressed. Multi-level, combination prevention strategies that integrate empirically-based interventions with trauma informed care have the potential to not only reduce vulnerability of HIV/STI, but also alter the nature of the social and structural determinants of women's health.

\section{Abbreviations}

ACE: Adverse childhood experience; ACS: American community survey; BRFSS: Behavioral risk factor surveillance survey; Cl: Confidence interval; HIV: Human immunodeficiency virus; IQR: Interquartile range; MSA: Metropolitan statistical area; NHBS: National HIV behavioral surveillance; PrEP: Pre-exposure prophylaxis; RDS: Respondent driven sampling; RR: Risk ratio; SES: Socio-economic status; SS: Successive sampling; STI: Sexually transmitted infection; US: United States

\section{Acknowledgments}

The authors are grateful to their dedicated interviewers, their community partners, and the participants of NHBS. The authors thank Senad Handanagic and Linda Drach for their helpful comments on the manuscript.

\section{Authors' contributions}

TWM conceptualized the study, analyzed the data, and wrote the manuscript. LEL conceptualized the study and made substantive intellectual contributions to the manuscript. $A B$ and VCD collected the data. RO conceptualized the study. All authors reviewed, edited, and approved the final manuscript.

\section{Funding}

NHBS is supported by the Centers for Disease Control and Prevention, PS161601, under grant number NU62PS005087 to TWM at the Oregon Health Authority. The funding source provided protocols and methods for data collection but did not have a role in data analysis or interpretation nor manuscript preparation.

\section{Availability of data and materials}

The datasets for current study are available from the corresponding author on reasonable request.

\section{Ethics approval and consent to participate}

All participants provided verbal consent for participation and HIV testing. Written, signed consent was waived to maintain the anonymity of the participants. The Oregon Health Authority's Science and Epidemiology Council and the Human Subjects Research Review Committee at Portland State University deemed NHBS to be public health surveillance (IRB\#163710).

\section{Consent for publication}

Not applicable.

\section{Competing interests}

The authors declare that they have no competing interests.

\section{Author details}

${ }^{1}$ HIV/STD/TB Section, Public Health Division, Oregon Health Authority, 800 NE Oregon Street, Portland, Oregon 97232, USA. ${ }^{2}$ Oregon Health \& Sciences University (OHSU), Portland, Oregon, USA. ${ }^{3}$ Multnomah County Health Department, Portland, Oregon, USA. ${ }^{4}$ Portland State University, Portland, Oregon, USA.

Received: 18 May 2020 Accepted: 24 September 2020 Published online: 02 October 2020

\section{References}

1. CDC. Women | Gender | HIV by Group | HIV/AIDS | CDC [Internet]. 2019 [cited 2019 Nov 25]. Available from: https://www.cdc.gov/hiv/group/ gender/women/index.html.

2. Frew PM, Parker K, Vo L, et al. Socioecological factors influencing women's HIV risk in the United States: qualitative findings from the women's HIV Serolncidence study (HPTN 064). BMC Public Health. 2016;16(1):803. 
3. Brawner BM. A multilevel understanding of HIV/AIDS disease burden among African American women. J Obstet Gynecol Neonatal Nurs. 2014;43(5):633-E50.

4. Grant MG. Let's Call Sex Work What It Is: Work | The Nation. The Nation [Internet] 2014 [cited 2018 Nov 9];Available from: https://www.thenation. com/article/lets-call-sex-work-what-it-work/.

5. Paz-Bailey G, Noble M, Salo K, et al. Prevalence of HIV among U.S. female sex workers: systematic review and meta-analysis. AIDS Behav. 2016;20(10): 2318-31.

6. CDC. HIV Infection, Risk, Prevention, and Testing Behaviors among Heterosexuals at Increased Risk of HIV Infection-National HIV Behavioral Surveillance, 20 U.S. Cities, 2013. 2013;(13):28

7. Chen Y-H, McFarland W, Raymond HF. Behavioral surveillance of heterosexual exchange-sex partnerships in San Francisco: context, Predictors and Implications. AIDS Behav. 2011;15(1):236-42.

8. Cohan DL, Kim A, Ruiz J, et al. Health indicators among low income women who report a history of sex work: the population based northern California young Women's survey. Sex Transm Infect. 2005;81(5):428-33.

9. Decker MR, Miller E, McCauley HL, et al. Sex trade among young women attending family-planning clinics in northern California. Int J Gynaecol Obstet. 2012;117(2):173-7.

10. Jenness SM, Kobrak P, Wendel T, et al. Patterns of exchange sex and HIV infection in high-risk heterosexual men and women. J Urban Health. 2011; 88(2):329-41.

11. Sherman SG, Hast M, Park JN, et al. Correlates of exchange sex among a population-based sample of low-income women who have heterosexual sex in Baltimore. AIDS Care. 2018;30(10):1273-81.

12. Walters SM, Rivera AV, Reilly $\mathrm{KH}$, et al. Exchange sex among persons who inject drugs in the New York metropolitan area: The importance of local context, Gender and Sexual Identity. AIDS Behav. 2018;22(9):2773-87.

13. Glick SN, Burt R, Kummer K, et al. Increasing methamphetamine injection among non-MSM who inject drugs in King County, Washington. Drug Alcohol Depend. 2018;182:86-92.

14. Golden MR. Outbreak of Human Immunodeficiency Virus Infection Among Heterosexual Persons Who Are Living Homeless and Inject Drugs - Seattle, Washington, 2018. MMWR Morb Mortal Wkly Rep. 2019;68 [cited 2019 Dec 16], Available from: https://www.cdc.gov/ mmwr/volumes/68/wr/mm6815a2.htm.

15. OHA. Oregon Health Authority : HIV Infection Among People Who Use Drugs : HIV Data : State of Oregon. 2019 [cited 2019 Dec 16]. Available from: https://www.oregon.gov/oha/PH/DISEASESCONDITIONS/

COMMUNICABLEDISEASE/DISEASESURVEILLANCEDATA/HIVDATA/Pages/HIV_ Cluster.aspx.

16. Ahrens KR, Katon W, McCarty C, et al. Association between childhood sexual abuse and transactional sex in youth aging out of foster care. Child Abuse Negl. 2012;36(1):75-80

17. Fang L, Chuang D-M, Lee Y. Adverse childhood experiences, gender, and HIV risk behaviors: results from a population-based sample. Prev Med Rep. 2016:4:113-20.

18. Wingood GM, Diclemente RJ, Mikhail I, et al. HIV discrimination and the health of women living with HIV. Women Health. 2007:46(2-3):99-112.

19. Romero-Daza N, Weeks M, Singer M. "Nobody gives a damn if I live or die": violence, drugs, and street-level prostitution in inner-city Hartford, Connecticut. Med Anthropol. 2003;22(3):233-59.

20. Pence BW, Reif $\mathrm{S}$, Whetten $\mathrm{K}$, et al. Minorities, the poor, and survivors of abuse: HIV-infected patients in the US deep south. South Med J. 2007; 100(11):1114-22.

21. CDC NHBS. National HIV Behavioral Surveillance (NHBS) | Surveillance Systems | Statistics Center | HIV/AIDS | CDC. 2018 [cited 2018 Oct 15]. Available from: https://www.cdc.gov/hiv/statistics/systems/nhbs/index.html.

22. Gallagher KM, Sullivan PS, Lansky A, et al. Behavioral surveillance among people at risk for HIV infection in the U.S.: the National HIV Behavioral Surveillance System. Public Health Rep Wash DC 1974. 2007;122(Suppl 1):32-8.

23. O'Leary A, Martins P. Structural factors affecting women's HIV risk: a lifecourse example. AIDS. 2000;14:S68.

24. Heckathorn DD. Respondent-driven sampling: a new approach to the study of hidden populations. Soc Probl. 1997;44(2):174-99.

25. Wade R, Becker BD, Bevans KB, et al. Development and evaluation of a short adverse childhood experiences measure. Am J Prev Med. 2017;52(2):163-72.

26. Handcock MS, Fellows IE, Gile KJ. RDS analyst: analysis of respondent-driven sampling data. Los Angel CA; 2013.
27. Gile KJ. Improved inference for respondent-driven sampling data with application to HIV prevalence estimation. J Am Stat Assoc. 2011; 106(493):135-46.

28. American FactFinder - Results [Internet]. 2018 [cited 2018 Oct 17];Available from: https://factfinder.census.gov/faces/tableservices/jsf/pages/productview. xhtml?pid=ACS_16_5YR_B17001\&prodType=table.

29. NHANES. NHANES 2015-2016: Sexual Behavior Data Documentation, Codebook, and Frequencies [Internet]. 2018 [cited 2018 Oct 17]. Available from: https://wwwn.cdc.gov/Nchs/Nhanes/2015-2016/SXQ_I.htm\#SXD021.

30. Sun G-W, Shook TL, Kay GL. Inappropriate use of bivariable analysis to screen risk factors for use in multivariable analysis. J Clin Epidemiol. 1996; 49(8):907-16.

31. Farrar DE, Glauber RR. Multicollinearity in regression analysis: The problem revisited. Rev Econ Stat. 1967;49(1):92-107.

32. Merrick MT, Ford DC, Ports KA, et al. Prevalence of adverse childhood experiences from the 2011-2014 behavioral risk factor surveillance system in 23 states. JAMA Pediatr. 2018;172(11):1038-44.

33. Gibbs A, Dunkle K, Washington $L$, et al. Childhood traumas as a risk factor for HIV-risk behaviours amongst young women and men living in urban informal settlements in South Africa: a cross-sectional study. PLoS One. 2018;13(4):e0195369

34. Bernstein DP, Stein JA, Newcomb MD, et al. Development and validation of a brief screening version of the childhood trauma questionnaire. Child Abuse Negl. 2003;27(2):169-90.

35. Campbell JA, Walker RJ, Egede LE. Associations between adverse childhood experiences, high-risk behaviors, and morbidity in adulthood. Am J Prev Med. 2016;50(3):344-52.

36. Greenberg DM, Baron-Cohen S, Rosenberg N, et al. Elevated empathy in adults following childhood trauma. PLoS One. 2018;13(10):e0203886.

37. The Lancet. Opioids and methamphetamine: a tale of two crises. Lancet. 2018;391(10122):713.

38. OHA. Oregon Health Authority : Prescribing and Overdose Data for Oregon Opioid Overdose and Misuse : State of Oregon. 2018 [cited 2018 Nov 2]. Available from: https://www.oregon.gov/oha/PH/PREVENTIONWELLNESS/ SUBSTANCEUSE/OPIOIDS/Pages/data.aspx

39. Ellis MS, Kasper ZA, Cicero TJ. Twin epidemics: The surging rise of methamphetamine use in chronic opioid users. Drug Alcohol Depend. 2018;193:14-20.

40. Lopez A. The Co-Use of Methamphetamine and Opioids Among Patients in Treatment in Oregon, USA. 2019 [cited 2019 Dec 16]. Available from: https:// ndews.umd.edu/sites/ndews.umd.edu/files/pubs/NDEWS-Hotspot-SerenityLane-Sept2019-FINAL.pdf.

41. Auerbach JD, Kinsky S, Brown G, et al. Knowledge, attitudes, and likelihood of pre-exposure prophylaxis (PrEP) use among US women at risk of acquiring HIV. AIDS Patient Care STDs. 2015;29(2):102-10.

42. Reuben A, Moffitt TE, Caspi A, et al. Lest we forget: comparing retrospective and prospective assessments of adverse childhood experiences in the prediction of adult health. J Child Psychol Psychiatry. 2016;57(10):1103-12.

43. Gile KJ, Handcock MS. Respondent-driven sampling: an assessment of current methodology. Sociol Methodol. 2010;40(1):285-327.

\section{Publisher's Note}

Springer Nature remains neutral with regard to jurisdictional claims in published maps and institutional affiliations.

Ready to submit your research? Choose BMC and benefit from:

- fast, convenient online submission

- thorough peer review by experienced researchers in your field

- rapid publication on acceptance

- support for research data, including large and complex data types

- gold Open Access which fosters wider collaboration and increased citations

- maximum visibility for your research: over $100 \mathrm{M}$ website views per year

At BMC, research is always in progress.

Learn more biomedcentral.com/submission 